This is the pre-peer reviewed version of the following article: Duncombe, R. \& Heeks, R. "Enterprise across the digital divide: information systems and rural microenterprise in Botswana", Journal of International Development, 14(1), 2002, 61-74, which has been published in final form at:

http://onlinelibrary.wiley.com/doi/10.1002/jid.869/abstract

\title{
Enterprise Across the Digital Divide: Information Systems and Rural Microenterprise in Botswana
}

\author{
Richard Duncombe and Richard Heeks \\ Institute for Development Policy and Management \\ University of Manchester \\ England
}

Corresponding author: Dr Richard Heeks, IDPM, University of Manchester, Precinct Centre, Manchester, M13 9GH. Tel: 0161-275-2870. Fax: 0161-273-8829. Email:

richard.heeks@man.ac.uk 


\begin{abstract}
This paper focuses on the role of information and information-handling technologies within the many rural microenterprises that currently lack access to ICTs. On the basis of field research in Botswana, it finds that poor rural entrepreneurs rely heavily on informal, social and local information systems. While highly appropriate in many ways, these systems can also be constrained and insular. Priorities for breaking this insularity will be greater access to shared telephone services. ICTs may play a supplementary role. They will need to be based in intermediary organisations that can provide complementary inputs of finance, skills, knowledge and other resources.
\end{abstract}

\title{
Introduction
}

The work reported here lies at the intersection of two development trends, discussed briefly below.

First, growing recognition of the critical development role of micro- and small enterprises (MSEs). Arguably their most important contribution is to employment creation and income generation for poor and disadvantaged populations (Daniels, 1999; ILO, 2000). There are wider macro-economic benefits of a vibrant MSE community, providing economic flexibility and turning household savings that would otherwise be lost to consumption into local investments.

MSEs also make social contributions to development, through self-development, enabling individuals - often poor women - to gain experience and confidence and to enhance skills, as well as providing for collective development through communitybased organisations such as co-operatives (Creevey, 1996; Liedholm and Mead, 1999). MSEs therefore make an important contribution to both social and economic development.

The second development trend is growing recognition of the critical development role of information/knowledge and of information and communication technologies (ICTs). This role will not be reprised here since it is described elsewhere in this special issue and in other sources (World Bank, 1998; Heeks, 1999; DOT Force, 2001).

Despite the importance of both development trends, little work has been undertaken at their intersection, reviewing the role of information and ICTs in micro- and small enterprise. The research reported here set out to fill that knowledge gap in order to better understand how ICTs may or may not contribute to the development process.

\section{Research Focus and Approach}

Within the overall family of MSEs, the research focussed on the type of enterprise that - in numeric terms - forms the majority of those in developing countries. That is, enterprises which are informal sector and unregistered, which are rural, and which are 'micro' (less than 10 employees) in size (Liedholm and Mead, 1999; ILO, 2000). 
These rural microenterprises (MEs) are typically survivalists and trundlers, not flyers (see Box 1). One may even question whether the word 'enterprise' conjures the correct image. Their impact at a macro level is limited in terms of wealth creation, growth, innovation, value-added, exports, etc. However, they are critical to the livelihoods of hundreds of millions of poor women and men in developing countries, and they have the most direct relationship to poverty alleviation of all enterprise types (Daniels, 1999; Mead, 1999).

\section{Box 1: Micro/Small Enterprise Categories \\ Adapted from Grindle et al (1989) and Mead (1994)}

Survivalists: enterprises run by those who have no choice but to take up the incomegenerating activity because they have no other source of livelihood. Income provided may be poverty-line or even sub-poverty-line. Most 'enterprises' in developing countries (DCs) are of this type.

Trundlers: those where enterprise turnover is roughly static and whose entrepreneurs show no great desire or no great capacity to expand. Income provided will be enough to meet basic needs. These form the second-largest group of small enterprises in DCs.

Flyers: enterprises run by true entrepreneurs who have taken up enterprise because they see opportunities for growth. Income levels may meet more than basic needs, and enterprises may graduate to the medium-scale category. Only a very small proportion of DC small enterprises falls into this category.

Given the lack of current knowledge, the work undertaken needed to adopt a 'back to basics' approach that analysed the current role of information and informationhandling technologies within the 'lives' of microenterprises. It also needed to address the particular challenge for application of ICTs: ascertaining how to reach out to such enterprises, which currently lie on the wrong side of the digital divide - not owning ICTs or telecommunications facilities and, in many cases, having no access to such facilities. Only by such outreach will ICTs provide a categorical contribution to poverty alleviation in developing countries.

This type of approach required the use of case study methods, with data gathered by interview and observation in microenterprises. This was supplemented by data from interviews in other stakeholder organisations including enterprise-support agencies (ESAs), government and donor organisations, consultants and - for comparison urban microenterprises. This work was undertaken in the North-East region of Botswana, selected for its wide range of rural microenterprise, some of which had access to telecommunication services. More detail about the fieldwork is provided in Appendix 1.

\section{Past Findings about Rural MSEs}

Before reporting the findings of field research, it will first be useful to review the few clues about information and about ICTs provided by past surveys of rural MSEs in 
Botswana $^{1}$. The Botswana SMME Task Force (1998) did emphasise the extent to which entrepreneurs lacked information about available sources of assistance. It was concluded, for example, that only $7 \%$ of micro- and small-scale business owners were aware of most finance and business assistance programmes and, more strikingly, that only $27 \%$ were aware of the availability of Botswana's high-profile Financial Assistance Programme. Other than this, however, information was not considered in previous studies, leaving a large knowledge gap for the current research to fill.

There was also little evidence relating to information and communication facilities: these issues were not directly considered in the earlier Botswana surveys. What evidence there was, however, did point to a range of factors that heighten information and communication problems (Lisenda, 1997):

- Remote locations. MSEs need reliable access to the available infrastructure from their localities. Yet the majority were found to have no access or restricted/unreliable access to information and communication services/networks.

- Lack of education/literacy. $88 \%$ of all MSE owners were found to have only primary schooling or no education, whilst only $1 \%$ had some form of tertiary education. Many will therefore lack sufficient literacy, education and training to access, assess and apply information inputs.

- Poor business skills. 80\% of MSEs keep no internal records: not just financial records (e.g. cash book, expense ledger, etc) but also records of transactions such as invoices, receipts, etc. This suggests little or no scope for the application of ICT-based systems in a direct business support role.

- Poverty/lack of affordability. The majority (69\%) of MSEs generate average annual turnovers of c.US\$1,250, considerably less than the price of a single PC. Most microenterprises are therefore too small to justify or afford direct investment in computer-based ICTs.

- Lack of transport. Census data shows that in 1994, only $8.5 \%$ of rural households owned a vehicle, rising from $4.8 \%$ in 1986 (CSO, 1996). This severely constrains access to the 'outside world' and its information and communication facilities.

Thus, past evidence suggests that the basic requirements (access, affordability and skills) are not yet in place for the direct application of ICT-based systems within most rural micro- and small enterprises. Intermediated models will therefore be the norm. This required the current research to incorporate more detailed consideration of ways in which existing institutions can provide access for enterprises - directly or indirectly - to ICTs.

\section{Findings From Current Case Studies}

The following section provides details of the findings drawn from interview and observational field data. It focuses particularly on the role of information, of information-handling technologies, and of information intermediaries in the lives of rural microenterprises.

\footnotetext{
${ }^{1}$ The term 'MSE' will be used in this section since the surveys covered enterprises of up to 20 employees. In practice, though, the vast majority of those covered by earlier surveys fell into the microenterprise category.
} 


\section{Information and Microenterprise}

The main information-related characteristics and constraints of the case study microenterprises are outlined below.

Dominance of the informal, social and local. Information acquired by the enterprises surveyed was overwhelmingly informal in nature. It was mainly transmitted verbally and generally remained unrecorded or poorly recorded. A basic cash book was the only form of record found in these enterprises.

In terms of information networks, case study owners relied on personal contacts in the immediate locality including business contacts, friends and family members. Three network types were identified, enabling an information network diagram to be drawn up (see Figure 1):

- Social networks - those based on individual, non-market links - dominated.

- Institutional networks - those based on non-market links to government, nongovernmental and private institutions - were also important, at least in the study group.

- Business networks - those based on contractual, transactional relationships between enterprises - were limited and had a strong social component.

\section{Figure 1: Schematic Representation of Enterprise Information Networks}



Environmental Information

Social networking was clearly vital to the microenterprises. Enterprise owners wanted and needed information obtained from their immediate environment, from trusted and familiar sources. For example, those businesses offering informal credit arrangements preferred to deal with customers who were within easy reach and who were part of the vendor's social network. 
However, this type of social networking had its downsides. Reliance on localised, social network-based, informal information may be a necessity for these microenterprises, but such information was sometimes of poor quality and it prevented them meeting their need to extend their market reach in order to attract new/larger customers. For such enterprises, informal information systems represented a major constraint. Some entrepreneurs wished to access formal credit facilities requiring written applications. Some wished to collect information on market prices within urban areas. Some needed to look further afield for raw materials, comparing prices and availability of inputs. Some even needed to take greater account of the legal/regulatory framework within which they were operating. In meeting all of these needs - supply-, environment- and demand-related - current informal, social, localised information networks held them back, perpetuating an insular existence for these enterprises.

This type of information network appeared to particularly fail the poorest and most disadvantaged entrepreneurs in the study, such as female-headed enterprises. Not only did they lack business networks but their social networks were also small and knowledge-poor. Those who lack social capital can be locked into livelihoods of poverty and inequality (Barr, 1998), and this seemed to be the situation for the women running a number of these microenterprises.

What support did institutional networks provide? When they intervened, enterprisesupport agencies were undoubtedly trying to help and often did help in a direct, shortterm sense. However, they often substituted for the business linkages that would probably be far better at providing the information MEs really needed. In comparison with business linkages, the institutional linkages were often more formal, less flexible and reduced the self-reliance of entrepreneurs, creating a sense of long-term dependency.

But one must be realistic. Given the importance of social factors in these enterprise's lives and, for rural microenterprises, the limited number of nearby enterprises, it is easier to prescribe more formalised business networks in theory than it is in practice. Thus, for some enterprises, it may be unfair to compare the weakness of institutional information links with the strength of business information links since the latter are far harder to create than the former.

Information and resource needs. Each enterprise had particular needs for information but, for most, in the balance between supply-, environment- and demandrelated information, the most critical problem appeared to be in access to and availability of demand-/market-related information. A few enterprises had received assistance from enterprise-support agencies through the provision of supply-side information (e.g. about finance, technology and raw materials), and had even received direct assistance in obtaining such inputs. There was clearly a need for such inputs and related information: primarily dealing with working capital, management skills and a means of transport. However, too little support had been forthcoming on the demand side, in helping entrepreneurs find out about and secure new customers and markets. 
Supply-side interventions by government and NGO agencies had generally been made in the absence of demand-related information. Thus enterprises found themselves provided with technology or training or finance to help produce goods or services for which no clear market had been identified. These interventions were sometimes of little value because they failed to make demand-related information their starting point. In some cases, that information would have indicated no viable market for the proposed outputs.

Where either supply- or demand-related information was provided, these rural microenterprises often lacked the resources needed to take that information especially formal or ICT-based information from outside their social networks through to decisions and actions. Resources lacking for this 'information chain' included knowledge, motivation and skills (see Heeks' editorial in this collection). The provision of new information may therefore be a relatively low priority unless these other resources can be provided.

Going further, there was a sense that approaching survivalist/trundler microenterprises from a business viewpoint may be a mistake. Some of them face fundamental constraints - lack of market, lack of motivation, lack of capabilities - that cannot be overcome. They must therefore be viewed from a welfare, not a business perspective.

\section{Information-Handling Technologies and Microenterprise}

By dint of the boundaries initially set, none of the microenterprises surveyed was making use of ICTs, so no conclusions can be drawn about actual impacts. A few did make occasional use of a telephone, and evidence here was almost universally positive, as it has been in other studies of phone use by microenterprise (Barton and Bear, 1999; TDG, 2000). Use of a phone had reduced costs (e.g. by substituting for a journey) or increased income or reduced uncertainty in transactions with suppliers or customers. By reducing the uncertainty surrounding transactions, phones had also helped reduce entrepreneur's risks, making them more confident at the margin about innovation and about new input/output relationships.

The present cases reinforced the findings of past studies, that individual ownership models are suspect on access, cost and skills grounds. For example, individual ownership of ICTs would have represented an unaffordable addition to costs for all contacted enterprises (see Box 2). The priority for business expenditure for these enterprises (when cash was available and when household expenditure was not a higher priority) was purchase of materials and consumables or purchase of transport services for the delivery or collection of goods.

\section{Box 2: Cost of ICTs for Microenterprises}

Consider the total financial outlay for an individual wishing to have access to the Internet in Botswana. Telephone line connection and rental will cost US $\$ 105.40$ per annum. Local call charges will be levied at US\$0.60 per hour. Add to this average Internet access charges of US $\$ 15.00$ per month. This would produce a total annual running cost of US $\$ 441.40$ per annum (assuming five hours per week online). For the microenterprises surveyed, this represents between $25 \%$ and $50 \%$ of total annual 
enterprise revenue. Yet this excludes the cost of computer ownership - hardware, software, peripherals, training, etc - which would add at least a further US\$500 per year.

Individual ownership of a phone might have been viable for a few of the enterprises but, even then, it is quite possible that costs would outweigh benefits. Therefore - as discussed in the next section - the focus needs to be on access to intermediary-based information and communication services.

\section{The Role of ICT Intermediaries}

The vast majority of microenterprises - including those researched here - lack, and cannot afford, individual access to ICTs. Intermediaries offering access and support will be essential if the benefits of ICTs are to be brought to the poor in developing countries. They are needed to overcome barriers of cost, skills and absence of many other resources needed to turn information into decisions and actions.

There is a wide range of intermediaries that could potentially play this role:

- Enterprise-support agencies.

- Agricultural extension services/research and development organisations.

- Education and training establishments and support networks.

- Internet service providers and other private sector information service providers.

- Non-governmental agencies and community-based organisations.

- Health services, clinics and health posts.

- Local government offices and community centres.

- Terrestrial media including local TV and radio stations.

- Publicly-accessible telecommunication facility (e.g. payphone) providers.

- Other organisations including post offices, banks, etc.

Focusing specifically on those institutions already in the business of enterprise support, evidence from Botswana showed mixed levels of ICT take up. Many local agencies were constrained in the same way as individual enterprises by lack of skills, finance and infrastructure. NGOs and private sector agencies had been quicker at implementing ICT-based systems than government-funded organisations (including central and local government-run services). NGOs particularly were able to take advantage of promotional funding from donors and others that had been earmarked for ICT-based systems.

What, then, about the opportunities for intermediation via these NGOs given that they have been active both with MEs and with ICTs? From the agencies contacted and other interview sources, it was found that non-governmental enterprise-support agencies had undertaken widespread implementation of ICTs to support internal management systems within their organisations. However, there were also instances of the value of the ICT intermediary role in provision of both supply- and demandrelated information to external microenterprise clients. The Rural Industries Innovation Centre, for example, had used Internet access to obtain data that was then employed to improve the design of technologies and training for rural ME clients. 
Interview and observation data suggested that intermediation faced a number of challenges:

Need to add value to data. A key test of the worth of an intermediary will be the extent to which it can add value to data provision. If it merely provides access to ICT-borne data, then it fails to overcome many of the skill, knowledge and other resource deficits that prevent enterprises turning data into action. Rather, the intermediary should try to help enterprises not just access data but also to encompass the whole information chain by assessing, applying and acting on that data.

Need for direct, personal contact. All five ESA case studies illustrated the limits of ICT-based networks and the difficulties of achieving the 'last mile of connectivity' to microenterprises. Difficulties arose not only because poor entrepreneurs lack access to either ICTs or telecommunications, but also because they would only act upon, and trust, information delivered on a personal level. Intermediated information therefore had to be delivered to them face-to-face, which is very costly; so costly for many remote entrepreneurs that it does not happen.

Skewing agency attention away from clients. The information systems of support agencies - primarily externally-funded NGOs - were becoming more highly computerised and an increasing number of ICT-based information tools were being utilised by them.

This development can be seen in both a positive and negative light. On the one hand, it is enabling local enterprise-support organisations to build a technological and skills capacity that will improve their effectiveness in interacting with other ICT users in the private sector, in government and in the wider donor and NGO community. This could enable agencies to promote small business more effectively, for example through e-commerce and Web-based fair-trading.

On the other hand, utilisation of emerging technologies is causing local agencies to become more remote from their client populations. When ICTs arrive in an organisation, staff start paying more attention to the digital information systems and to digitally-connected individuals and organisations (Heeks, 2000). Connectivity through ICTs therefore tends to enhance upward and horizontal networking - to other agencies, to organisations abroad, to donors - but to inhibit downward networking between agencies and their poor, disadvantaged recipient populations (see also Kiraka and Manning's paper in this collection).

Lack of fit between agency and enterprise. Related to the previous issue is the more general need for enterprise-support agencies to understand and to appropriately support their client enterprises. It has been shown that, for this to happen, there needs to be a sufficient degree of 'fit' between agency and client along a number of key dimensions including organisational processes, structure, staffing and technology (Gibb and Manu, 1990). Some of the Botswana ESAs were trying to improve their fit, changing away from an older, more bureaucratic model to a newer, more entrepreneurial approach. 
However, the introduction of ICTs within the agencies was reducing this fit. Case study evidence illustrated a growing 'compatibility gap' between the increasingly ICTbased information systems used by support agencies and the non-ICT-based systems used by their target clientele in micro-/small enterprises. This will potentially reduce the ability of agencies to understand and to adequately support their microenterprise clients.

\section{Alternative Intermediaries: Suppliers}

A key trend in the provision of support for microenterprise has been the swing away from government support, even away from NGO support to some extent, and a greater recognition of the role that can be played by private sector institutions (World Bank, 2001). This must also be recognised in considering ICT intermediaries. As Barton (1997) notes and as demonstrated by all the cases in this study, key sources of information for MSEs are the other businesses in their network: suppliers, customers, sub-contractors, collaborators and competitors.

For rural microenterprises on the wrong side of the digital divide, are any of these likely to play the role of ICT intermediary? In most cases, no. Customers, collaborators and competitors were typically in the same boat: they were mainly nonICT users and were likely to remain so. Sub-contracting relationships were rare.

However, the same was not true of suppliers, some of whom did use ICTs. Suppliers often acted as the key link between microenterprises and the outside world.

Entrepreneurs showed a clear preference for suppliers who were able to provide goodquality, well-organised information. They also made use of that information to inform process, product and other decisions. Every enterprise has a supplier of some sort, whereas only a minority are touched by the activities of enterprise-support agencies. Suppliers have the advantage of better 'fit' with enterprises since, unlike most enterprise-support agencies, they are a business operating within the private sector. They are in a position to provide added value and they have a clear and direct commercial incentive to ensure that the ME (as a customer) makes effective use of the information provided.

Where suppliers were using ICTs, perhaps even more than 'official' enterprise-support organisations, they were acting as information intermediaries, mediating between the digital world of the Internet and the 'organic' world of the microentrepreneur. There will be 'last mile' compatibility and information inequality problems with suppliersas-intermediaries. Nevertheless, there needs to be greater recognition of the role played by suppliers, and greater thought given to ways in which suppliers can help bridge the gap between the two worlds described.

\section{Alternative Intermediaries: Telecentres}

In the Botswana study, there was no evidence of direct ICT support to rural microenterprise via models in use in other countries such as multi-purpose telecentres (communal facilities rooted around an Internet-linked PC). This is a model that has attracted considerable attention, but a model that has been characterised more by hype than by strong, objective analysis; and more by a technology-driven approach than by the required information- and needs-driven approach (Colle, 2000; Benjamin, 2001). 
Tschang et al's paper in this collection provides some clearer evidence but still leaves question marks over sustainability and provision of non-technological resources. Only once adequate answers start to be provided will a clearer picture emerge about the potential for telecentre-mediated support for microenterprise.

\section{Intermediated Telecommunications Services}

More widespread, affordable access to information and communication services in Botswana has, thus far, centred on a programme of village payphone provision by the national operator, Botswana Telecommunications.

In general, telephone-centred models seem to have proven their worth for both the local phone operator and, more importantly, for local users (Benjamin, 1999; TDG, 2000). Evidence is still very slim in relation to the specific impact on local microenterprises but the positive impact of these services for Botswana MEs has already been described above. One may conclude that it is phone shops/village payphones which represent the priority application of technology to information needs of DC microenterprises.

\section{Conclusions}

\section{Summary}

The type of enterprises that form the focus for this study - rural microenterprises not currently using ICTs - constitute the majority of enterprises in developing countries. They play a crucial role in poverty alleviation, and a greater understand of their information systems is a vital piece in the jigsaw of understanding and intervening in poverty alleviation.

The case study approach used, and the limited sub-national location selected, must necessarily place a significant 'health warning' on generalisation of the findings reported here. In summary, though, results from the case studies suggest that information needs of rural microenterprises are quite localised and likely to be met more by informal, organic information systems than by formal, ICT-based systems. Business owners placed greater value on information received through personal contact, and were able to build up greater trust in personalised information channels and sources.

Information delivered via social and non-commercial institutional linkages played a vital role for these enterprises. Institutional linkages particularly were seen as the single most important source of external information for non-ICT users since they tended to lack access to wider business networks. Yet such linkages also failed these poor, disadvantaged entrepreneurs. Institutional linkages could build dependency, and information from social linkages was often constrained and insular because the entrepreneur's social network itself was constrained in both size and quality. 


\section{Priorities for Information-Related Action}

On the basis of the limited evidence base, we conclude that information-poor microentrepreneurs are likely to be assisted in the first instance by strategies that help to improve natural support networks rather than by a strategy of formalisation. These strategies might include the strengthening of backward/forward business linkages, the provision of better local market/demand information, and the building of social capital through community networking, the development of personal communication skills, and support for more effective interpersonal networking.

Conversely, information received in a digitised form is generally non-personalised and distant, and lacks the trust components necessary when making decisions that may involve an element of risk. Environmental analysis suggests there are also likely to be substantial long-term financial, socio-cultural, and knowledge barriers that would need to be overcome before most entrepreneurs in this category could effectively utilise both ICTs and ICT-based information directly.

Putting these issues together, we find the main technology-related priority for such groups to be access to telephone services. This is the information-related technology that had done most to reduce costs, increase income and reduce uncertainty/risk amongst the target population. Phones support the current reality of informal information systems; they can help extend social and business networks; and they clearly substitute for journeys and, in some cases, for brokers, traders and other business intermediaries. They therefore work 'with the grain' of informality yet at the same time can help to eat into the problems of insularity that can run alongside. Phones also meet the priority information need of this group for communication rather than processing of information. For similar reasons, fax would be a secondary priority.

Telecommunications should be provided via a communal or other shared access model or - for those few with a high-enough turnover - via an enterprise-owned model. Recent growth in telephony and wider telecommunications - including mobile telephony - in Botswana and other developing countries is therefore to be welcomed (ITU, 2000).

Other information-related technologies should also be addressed for this group. As well as using organic social networks, current non-ICT users seem to access information mainly via intermediate channels (radio, TV) and literate channels (newspapers, newsletters, manuals) (see Heeks' editorial in this collection for further details). Such channels should probably be seen as the main delivery mechanism for formal information for rural microenterprises.

Where ICTs are used, they should provide a supplement, not a substitute, for existing information systems. In almost all cases intermediaries (and subsidised access) will be needed to bridge the financial, socio-cultural, and knowledge gaps experienced by current non-ICT users.

Priorities for application of such intermediated access to ICTs probably again lie in communication more than in processing of information. The formal information processing requirements of such enterprises were relatively limited, and could 
typically be met cost-effectively by improved paper-based methods. In communication of information, though, ICTs can substantially reduce costs and greatly increase access. The fourth technological priority - after phone and fax and non-digital information channels - would therefore be access to email followed by access to the Web.

ICTs have the potential to provide infusions of external information that break the insularity and quality deficits of some informal social networks. They can be a means for communicating market/demand information (though this can equally, perhaps more appropriately, be delivered by non-ICT means). They can also disseminate information; most eye-catchingly through Internet-mediated marketing of microenterprise products and services. However, it must be recognised that there may well be higher priorities than these ICTs; that Internet-based applications are no panacea; and that many complementary inputs and actions are required if microenterprises are to make use of the technology (for external marketing, for example), even via intermediaries.

\section{Differentiating Enterprise Types}

Both the message and the method reported here are rooted in the notion that one must understand the specific needs and contexts of particular enterprises. Understanding rural microenterprises in developing countries means understanding that the vast majority are survivalists or trundlers that provide poverty-line - even sub-poverty-line - incomes for 'entrepreneurs' who lack many key resources.

These entrepreneurs have particular characteristics that are not well recognised from a business perspective. Such characteristics include multiple occupations; family and other ties that are inseparable from income-generating activities; risk aversion; territoriality that allocates particular 'income spaces' to particular groups or individuals; and patron - client relations that constrain choices and behaviours (Grindle et al, 1989). Their need is often for welfare and social development interventions that reduce vulnerabilities.

Yet, too often, Western-inspired business models and interventions are imposed on these welfare clients. They are characterised not by the reality of vulnerable survivalists trying to keep their heads above water within a complex network of social relationships, but as individualised entrepreneurs who - with a nudge of business advice and a touch of venture capital - will metamorphose into dynamos of market capitalism.

The same danger awaits with ICTs: it will be far too easy to fall into the trap of bringing business weapons to a welfare war. Unless the social and cultural realities of the poor are recognised, and unless the true role of these 'enterprises' is understood, a lot of wasted investment of time, money and energy lies ahead.

In policy terms, too, these differences need to be recognised. Current national policies of relevance to ICTs in Botswana, for instance, have tended to be pro-growth, serving the information and communication needs of flyers and potential flyers. Policy has focused on partial deregulation of the telecommunications sector and on 
creation of quasi-independent regulators to oversee the liberalisation process. Such a market-led approach is having a positive impact on dynamic enterprises, as seen in the financial, technical services and tourism sectors, for example. Such a pro-growth, pro-flyer approach may also be sound in terms of long-term national development.

However, there are internal and external shorter-term pressures for pro-growth policies - promoting the benefits of ICTs for economic growth and development - to be balanced by pro-poor policies that address survivalists and trundlers. ${ }^{2}$ Pro-poor policies must emphasise the real information needs of rural microenterprises and support information systems (including intermediated ICTs where appropriate) which are affordable, accessible and usable by all members of the enterprise sector.

\section{References}

Barr AM. 1998. Enterprise Performance and Functional Diversity of Social Capital, Working Paper Series/98-1, Centre for the Study of African Economies, University of Oxford, Oxford.

Barton C. 1997. Microenterprise Business Development Services, Microenterprise Best Practices, Bethesda, MD.

Barton C, Bear M. 1999. Information and Communication Technologies: Are they the Key to Viable Business Development Services for Micro and Small Enterprises?, Microenterprise Best Practices, Bethesda, MD.

Benjamin P. 1999. Universal Access Review, No.1 of 1999, International Development Research Centre, Ottawa. http://www.idrc.ca/cgishell/lyris.pl?visit=telecentres-1\&id=110218025

Benjamin P. 2001. Community development and democratisation through information technology: building the new South Africa. In Reinventing Government in the Information Age, Heeks R. (ed.). Routledge, London; 194-210.

Colle R. 2000. Communication shops and telecenters in developing nations. In Community Informatics, Gurstein M. (ed.). Idea Group Publishing, Hershey, PA; 415445.

CSO. 1996. Living Conditions in Botswana: 1986 to 1994, Central Statistical Office, Gaborone, Botswana.

Creevey LE. 1996. Changing Women's Lives and Work, Intermediate Technology Publications, London.

Daniels L. 1999. The role of small enterprises in the household and national economy of Kenya, World Development, 27(1): 55-65.

\footnotetext{
${ }^{2}$ Pro-growth policies emphasise the 'trickle down' of economic and employment benefits resulting from technology-led growth and development. Evidence shows, however, that there may be a considerable time lag before such productivity and efficiency gains can be realised, given widespread institutional, organisational and managerial constraints (Freeman, 1996).
} 
DOT Force. 2001. Digital Opportunities for All: Meeting the Challenge, Digital Opportunity Task Force http://www.g7.utoronto.ca/g7/summit/2001genoa/dotforce1.html

Duncombe R, Heeks R. 2001. ICTs and Small Enterprise in Africa, IDPM, University of Manchester, Manchester http://www.man.ac.uk/idpm/ictsme.htm

Freeman C. 1996. Unemployment and the Diffusion of Information Technologies: The Two-Edged Nature of Technical Change, PICT Policy Research Paper No.32, Brunel University, Uxbridge, UK.

Gibb A, Manu G. 1990. The design of extension and related support services for small-scale enterprise development, International Small Business Journal, 8(3): 1026.

Grindle M. et al. 1989. The framework. In Seeking Solutions, Mann CK et al. (eds.). Kumarian Press, West Hartford, CT; 1-98.

Heeks R. 1999. Information and Communication Technologies, Poverty and Development, Development Informatics Working Paper No.5, IDPM, University of Manchester, Manchester. http://www.man.ac.uk/idpm/idpm dp.htm

Heeks R. 2000. Information technology, information systems and public sector accountability. In Information Technology in Context: Studies from the Perspective of Developing Countries, Avgerou C, Walsham G (eds.). Ashgate, Aldershot, UK; 201219.

ILO. 2000. World Labour Report, International Labour Organisation, Geneva.

ITU. 2000. World Telecommunications Indicators, International Telecommunications Union, Geneva.

Liedholm C, Mead D. 1999. Small Enterprise and Economic Development, Routledge, London.

Lisenda L. 1997. Small and Medium Enterprises in Botswana: Their Characteristics, Sources of Finance and Problems, BIDPA Working Paper No.14, Botswana Institute for Development Policy Analysis, Gaborone, Botswana.

Mead D. 1994. The contribution of small enterprises and policies to employment growth in Southern and Eastern Africa, World Development 22(12): 1881-94.

Mead D. 1999. MSEs tackle both poverty and growth (but in differing proportions). In Enterprise in Africa, King K, McGrath S (eds.). Intermediate Technology Publications, London; 61-70.

SMME Task Force. 1998. Small, Medium and Micro-enterprise Task Force Report, Ministry of Commerce and Industry, Government Printer, Gaborone, Botswana. 
TDG. 2000. Grameen Telecom's Village Phone Programme, TeleCommons Development Group, Ontario. http://www.telecommons.com/villagephone/

World Bank. 1998. World Development Report, World Bank, Washington, DC.

World Bank. 2001. Business Development Services for Small Enterprises: Guiding Principles for Donor Intervention, Committee of Donor Agencies for Small Enterprise Development, World Bank Group, Washington, DC.

http://www.ilo.org/public/english/employment/ent/papers/guide.htm 


\section{Appendix 1: Fieldwork Details}

Botswana was selected as the location for field research because of its pervasive MSE sector; its relatively well-developed ICT infrastructure; and its policy environment that was favourable to both MSE and ICT development (Duncombe and Heeks, 2001). Data gathering was focused on the country's North-East region because it is one of Botswana's poorest, containing a wide range of rural microenterprise, but with a reasonably well-developed physical infrastructure and some access to telecommunication services.

A case study approach was undertaken, with data gathered by interview and observation in 1999 in a total of 14 microenterprises that had employee numbers ranging from one to six. These microenterprises covered six main areas of economic activity: crafts, metalworking, food processing, livestock, poultry, and textiles/clothing. Interviews and extended visits were also undertaken in five enterprise-support agencies (ESAs) that provide assistance (including finance, training and technology) to rural MEs in Botswana.

In order to support and understand the case studies with the perspectives of other stakeholders, another 23 interviews were conducted within government and donor agencies, and within consulting organisations involved in enterprise development. A further four interviews were undertaken in urban microenterprises.

Most of the microenterprises included in this study were identified via the enterprisesupport agencies. Therefore the role of agencies and the presence of institutional links was greater than for the majority of MEs in Botswana, which typically have no such institutional relationship. For example, cash books were found in the surveyed enterprises more often than would be the norm: this was the result of agency encouragement and training. This caveat must be borne in mind in the discussion within the paper. 